\title{
Market-Driven Management: the Policy Implications
}

\author{
Nicola Bellini*
}

\begin{abstract}
The first policy implication of the diffusion of a Market-Driven Management approach is the same as the spreading of globalization, i.e. the obsolescence of industrial policies as traditionally designed and managed by Nation-States with the established toolbox of protectionism and subsidies, picking 'national champions', etc.

The growing asymmetry between the physical jurisdiction of political bodies and the global operation space of modern corporations feeds the apparent trend toward company 'denationalization'.
\end{abstract}

Keywords: Market-Driven Management; Global Markets; Policy Implications; Industrial Policy; Global Competition; Sustainable Globalization

\section{The Survival of the 'Weak State'}

Which are the policy implications of such a substantial re-orientation in interpreting corporate behavior such as the one suggested by market-driven management (MDM) (Lambin, 2000; Brondoni and Lambin, 2001; Webster, 2002; Brondoni, 2007)? If industrial policy is the way States try to interfere with the structure, conduct and performance of companies and industries in pursuit of 'superior' collective goals (growth, development, power etc.), then a significant change in the way companies perceive themselves and their relationship with the market cannot be without consequences for the way governments shape their industrial policies. In this paper I intend to provide a rough sketch and a short and preliminary discussion of the policy implications of the MDM approach.

MDM is tightly linked to the full realization of the globalization process. On the one hand, this long-term, demand-centered strategic approach can be most profitable within truly global markets; on the other hand, this approach contributes actively to globalization, by defeating protectionism. Unsurprisingly, then, the first policy implication of the diffusion of a MDM approach is the same as the spreading of globalization, i.e. the obsolescence of industrial policies as traditionally designed

\footnotetext{
*Full Professor of Management, Scuola Superiore Sant'Anna-Pisa (nbellini@ @ssup.it)
} 
and managed by Nation-States with the established toolbox of protectionism and subsidies, picking 'national champions', etc.

The growing asymmetry between the physical jurisdiction of political bodies and the global operation space of modern corporations feeds the apparent trend toward company 'denationalization'. Denationalization does not mean the full loss of national reference as in an imaginary 'Cosmocorp' (Ball, 1967). However the 'Who is us?' (Reich, 1991) syndrome emphasizes that it is impossible to define in an automatic and unambiguous way the nationality of companies within the global economy in terms of headquarters or plant location, or owners' or workers' nationality. There is no obvious relationship between company and collective interests in the global economy.

Within this scenario we can easily expect a weakening of Nation States and of their ability to promote economic development by directing companies (dirigisme). This is neither a new trend nor a new prediction. 'Weak States' (Crozier, 1987; Atkinson and Coleman, 1989) have been essential to the neo-liberal consensus, which has dominated economic policy since the 1980s (and even earlier), encouraging a sometimes naïve and mostly ideological end-of-history syndrome (Bellini, 2000).

The State not only has survived, but is hardly confined within the boundaries set by neo-classical economic orthodoxy through the theory of 'market failures' (Stiglitz, 1989). Of course, in an era of globalization States are less and less taking 'whether choices' (whether to accept integration in the international economy, whether to promote technological innovation etc.), but complex 'how issues' are still to be faced: about the speed, the paths, the sustainability etc. (Schmitz, 2007). The Mercantilist chromosomes of economic policy (the equation between wealth and power that has always provided, and still provides, more than enough justification for State involvement in the economy) are without doubt also still there (Bellini, 1996). Any 'report of death' would be - borrowing from Mark Twain - 'an exaggeration'.

One should not underestimate the ability of the State to change and adapt to the new scenarios of globalization. This has occurred, first of all, through the reshaping of the role of the State and of its policy styles. This phenomenon can be described as a shift away from patterns of policy making that assumed, at least in abstract terms, a capacity to control (if not command) private business on the basis of explicit and formalized powers. Policy styles then emerge that are characterized by informality, flexibility, the search for consensus and market conformity (i.e. policy additionality with minimum interference in the market mechanism, not mere subsidiarity). The apparatus of the States is progressively shaped with reduced attention to guaranteeing close co-ordination and unitary command of a wide range of policy tools (like in the widely discussed 'MITI model', reflecting the Japanese experience of the 1980s: Johnson, 1982). Governments thus focus on better guaranteeing the learning process ('intelligent governments'), the continuous adaptation of policies in response to feedback from the economy, and the capacity to build and manage policy networks for the design and implementation of complex policies (see later).

Leaving aside old dilemmas (vertical vs. horizontal policies; which criteria for 'picking the winners'; automatic vs. discretionary support; subsidies vs. real 
services etc.), 'new' industrial policies are increasingly and inherently pragmatic (Cohen, 2006; Bianchi and Labory, 2007), based on the realization that 'there is no shortage of arguments against industrial policy (...) but there is no shortage of responses to these criticisms either' (Cohen, 2006, 101).

Moreover, States are still uniquely powerful actors, having access to unique resources like large budgets, personnel, specialized skills and technical assets, access to media and a monopoly on the use of force both inside and outside the country. States' power relies on a unique source of power, i.e. political legitimation, that is directly linked to its special task of looking after the 'general interest' and after key preconditions for development like stability and security. Out of rhetoric, this places governments in a peculiar position, unlike other actors. Based on the "primacy of politics', governments are best positioned to see and act on the complex and vital interconnections between different dimensions: economic, social, political, environmental, cultural etc. Governments also interact with the symbolic infrastructure of the society and of the economy, impacting on image, culture, values etc. and therefore also on collective and individual perceptions and expectations.

At the same time private actors, even the most powerful multinational corporations, are 'weak'. Their resources are limited. Their behavior is constrained by the needs of economic accountability. Cultural and organizational biases impact on the way they manage information and learning and on the contents of their decision. Adam Smith's warning is, of course, still valid: 'The statesman who should attempt to direct private people in what manner they ought to employ their capitals would not only load himself with a most unnecessary attention, but assume an authority which could safely be trusted, not only to no single person, but to no council or senate whatever, and which would nowhere be so dangerous as in the hands of a man who had folly and presumption enough to fancy himself fit to exercise it' (Smith, 1976, 456). But 'it is also clear that the private sector is not necessarily better informed than the State and, as in the case of the State, its decision-making might be biased in favor of hightech, big, glamorous projects. The real difference in behavior seems to reside in businesses' greater aptitude to terminate bad projects' (Cohen, 2006, 101).

\section{Industrial Policy from Government to Governance}

Consistently with the above mentioned pragmatism, a 'good industrial policy' must be seen as 'a strategic process of discovery - coordinated by public and private actors and based on relevant information and business opportunities - that results in appropriate measures being taken by the public authorities' (Cohen, 2006; cf. Rodrik, 2004). In other words, pragmatism is a factor in the shift from industrial policies monopolized by the 'Government' to governance-based approaches. This shift is indeed fundamental in explaining the survival of the 'weak State' and yet it is often misunderstood.

Due to cultural inertia, conventional wisdom still underlines as dominant the old rationalistic interpretation of government that is so dear also to standard economic thinking. According to this view, the truly political process is (or should be) limited to problem formulation. Consensus building should make way for scientific knowledge (including management, as suggested by the new public management 
approach), as soon as the time comes to design policy measures and an implementation program. The implementation phase itself is considered a nonpolitical, technical and potentially programmable activity.

Contrary to this view, 'weak states' seem to expand the political dimension of their operations in their policy processes down to the implementation phases. The key point is the realization that public policy of any relevance is the result of interactions between public and private actors in all phases of the policy process.

Therefore, in a governance scenario a new unit of analysis emerges, substituting 'government' with the policy network. Policy networks not only diminish the governments' overload in both decision-making and implementation, but make additional and/or rare resources available (financial, political, human and relational resources) and above all allow to activate and manage collective learning processes in situations where no consensus exists with respect to the objectives of policy, and/or uncertainty exists with regard to the appropriateness of instruments to reach the objectives.

Policy networks are defined as '(more or less) stable patterns of social relations between interdependent actors, which take shape around policy problems and/or policy programmes' (Kickert et al., 1997). The establishment, selection and retention of relationships with other actors within policy-networks constitutes the essence of policy-making. Policy networks are characterized by:

- the interdependence between the actors and the absence (or low relevance) of hierarchical relationships;

- the variety of actors (public, private, collective, public-private etc.), each with their own set of objectives, values, perceptions, behavioral models and resources;

- a certain degree of stability throughout time of the relationship between the actors;

- the central role played by the interactive (learning) processes of integration between the objectives, the perceptions and the resources of the actors;

- the importance of social capital and therefore of improving the conditions for interaction between actors in the management of the policy network.

The management of policy networks can take place at two different levels. On the one hand, the structure of the network can be influenced, for example, through the composition, the number of actors, its openness, the internal rules, the introduction of new actors and the exclusion of some of the present actors, etc. On the other hand, at the cognitive level, it is possible to influence the perception, the views and expectations, to anticipate the exclusion of diverging ideas and views, to facilitate interaction and to promote a common language, to induce collective reflection and to prevent cognitive lock-in etc. Therefore the toolbox of industrial and innovation policies also includes a set of 'second generation' policy instruments (Bruijn and Heuvelhof, 1997; Bellini, 2006), which predominantly (although not exclusively) impact on the cognitive dimensions of local networks in the attempt to govern their evolution through the formation of perceptions and expectations. 


\section{Multi-Level Policy-Making}

States change also because they cannot be identified unequivocally with 'NationStates'. Contemporary States are a fragmented reality and government functions are designed and managed within complex multi-level systems.

On the one hand, we witness the shift to higher levels of coordination or, in the case of Europe, of straightforward policy action based on old and new tools of industrial policy, from regulation to the support of industrial champions, but with the opportunity to act on a higher, often unprecedented scale (Bianchi and Labory, 2006).

On the other hand, Nation States face the strengthening of the local level of government and especially of meso-levels such as the Regions. This is a phenomenon that is too widespread to be underestimated. It is not just confined to federal, quasi-federal or would-be federal countries. Devolution processes have occurred in the most diverse cases, from the UK to China. Even in traditionally centralized countries like Colbertian France the 'dirigiste end to dirigisme' that has characterized the 1980s and 1990s has led to a reshaping of State intervention since 2004 with a much greater emphasis on the pôles de compétitivité, with a new mobilizing role for local and regional governments (Cohen, 2007). Economic and industrial policies are deeply affected, not only for reasons of political legitimacy (economic regionalism) but also because of scale appropriateness with regard to some key issues of the knowledge economy (Bellini, 1996; Bellini and Landabaso, 2007; Cooke, 2008).

Fragmentation has two (partially conflicting) consequences. On the one hand, the complexity of policy making is substantially increased, especially to the extent that the relationships between different levels of government are not pre-determined and ruled hierarchically. Inter-governmental politics produces longer, sometimes more uncertain processes, based on bargaining, compromises and political exchange. As a result, choices and outcomes may be differentiated and favor 'better' governments and more advanced regions (as the two often coincide), while condemning less advanced areas to a vicious circle of backwardness and inadequate policies. At the same time, however, fragmentation feeds a pluralism of (competing) approaches that may result - if properly managed - in greater opportunities for policy experimentation and learning, greater flexibility and more opportunities of effective policy decisions.

\section{Challenges to Industrial Policy from MDM}

Two features of MDM are critical in challenging industry - State relationships. The first one is the emphasis on time: for 'market-bubble management' time is a decisive competitive factor. This marks a gap between the need for time compression and speed by companies and the longer 'time-to-market' that consensus-building processes and bureaucratic procedures impose on policies. While companies adapt their timing to the pace of the global market, States seem to expect that the economy adapts its pace to political time.

This is only partially true. Also policy making needs to face a different sense of time. This occurs especially when factors and resources, that may be decisive for 
economic policy, are 'un-planable'. This may happen either because of the serendipity of policy effects (i.e. not all effects of a certain policy action can be identified and foreseen ex ante) or because threats and opportunities are exogenous and it is not possible to detect, not to say control, them sufficiently in advance. This happens, e.g., in the case of inward investment policies, where local governments, but even more sophisticated structures, cannot have full and timely information about the investment plans of foreign corporations. As a consequence, policies need to focus increasingly on preconditions that would allow to respond to threats or to exploit windows of opportunity as promptly as possible, one precondition being the setting up of cohesive, team-like policy networks with sufficient 'social capital'.

The second challenge to industry - State relations derives from the market-driven company's abandoning of the closed markets in order to act on the global scale. This scenario is characterized by structural instability. Instability is at the same time exogenous and therefore 'suffered' by companies, but is also planned and looked for (as in market-bubble management). The management of instability implies a dramatic emphasis on some crucial intangible assets, like brands, corporate culture and information systems (Brondoni, 2007). All of those assets concern cognitive functions and have to do with reputation, intelligence and learning.

Intangible assets, however, require time and investments to be established, maintained and updated as well as to be appreciated in their actual economic value. Can companies (both small and large) be expected to produce, maintain and update those assets effectively, timely and adequately? Of course these assets result from the autonomous ability of the company to design an organization and a strategic approach that meet these requirements, but some key components need to be extracted from the context. Thus, large multinational corporations, far from being 'rootless', are the ones that are most able to meet the challenges of globalization exactly because their culture and information systems are rooted in a variety of territories and their organization is able to combine creatively and effectively this wealth of context-specific, intangible resources.

\section{Sustainable Globalization}

If MDM literature emphasizes the role of corporate culture, both practitioners and scholars of industrial policy should show greater awareness of the extent to which local cultures impact on companies. Of course this is not a one-way, deterministic relationship: local cultures shape corporate cultures as much as they are shaped by the latter (cf. Gatti, 2007). These interactions may be virtuous as well as vicious: local cultures and their manipulation through symbols, place brands and images (Bellini et al., 2008) may provide opportunities and resources, but also handicaps and constraints. Different cultures of innovation do matter to support corporate innovation (Didero et al., 2008) and the local 'culture of openness' provides assets to internationalization.

In fact, contemporary debates often reflect an 'ideology' of globalization which is shaped by its economic dimension and which suggests to policy-makers that internationalization is a process which is mainly economic and intrinsically positive. 
This view implies that the role of policies must be essentially one of supporting economic processes. This view, however, is partial and misleading. Internationalization has various aspects - economic, socio-cultural, and institutional which are strongly interconnected and which have to progress in a parallel or at least in a balanced way, otherwise they may turn into costs which easily become unsustainable for the area and which will block development. It is not necessary to be 'anti globalization' and/or protectionist, in order to adopt a more nuanced and critical view of the processes of internationalization. Numerous examples can be given which will lead to reflect on the concept of 'unbalanced development' and the negative repercussions it may have. On the social level, one may think of illegal immigration and related criminal activities. With respect to healthcare, there is the cyclically returning risk of 'pandemics', which make traveling more dangerous (with obvious social and economic repercussions). In the economy, internationalization may lead to concentration of economic power, oligopolies, disrupting competition etc. (Bellini and Bramanti, 2008; Bellini, Bramanti and Ongaro, 2008).

Outward internationalization lends itself to analogous reflections. For example, social and economic sustainability problems are related to sometimes massive delocalization processes. The investments of small and medium-sized Italian companies in Rumania, do not always bring about conditions for real growth for the local economies in the host country, as companies are mainly aiming at exploiting the low labor cost and the 'tolerance' of the local authorities.

To summarize, the analysis and evaluation of internationalization processes and the accompanying policies, should not only meet the requirements of effectiveness, efficiency, credibility, etc., but should also adhere to requirements with regard to economic, social and cultural sustainability and we must acknowledge that companies often contribute to, but do not necessarily produce socio-cultural sustainability.

What can be a policy framework in the era of globalization that is consistent with all the challenges and constraints that have been discussed so far?

In the era of globalization cognitive internationalization has emerged: it is in the strict sense the internationalization of knowledge, i.e. the process of the construction of a transnational base of processes which regard the production, circulation and application of knowledge. This does not necessarily imply the suppression of variety and identities, but may lead to a better exploitation of them. Local knowledge may then be codified and made global and eventually be reinterpreted and re-contextualised. Through this circuit the original local cognitive system opens up to the global network, and the global network opens up to the local cognitive system of destination (Grandinetti and Rullani, 1996). In other words, internationalization is viewed as a learning process which is incremental and not deterministic. It is based on the development of international networks of trust and on the accumulation of experiential knowledge, which generate the ability to exploit and explore and therefore to create commitment to external markets overcoming obstacles resulting from a lack of resources and knowledge (Johanson and Vahlne, 1990). This is true both at corporate and territorial level. Internationalization is therefore a process which generates specific, global-minded 'relational capital' and 'knowledge capital' and which tends to be self-reinforcing both in a quantitative and a qualitative way. 
Both the analytical and the normative perspectives should then lead us to revise the policy framework that is used to confront globalization and to escape from the traditional 'triangle' of the policies of protection (from imports and from 'undesirable' inward investments), projection (through the promotion of exports and of 'desirable' outward investments) and attraction (of investments, technologies, tourists and inhabitants. All these policies are in fact likely to be ineffective or by-passed within a scenario of market-driven globalization.

Other policies should then come to the forefront (Bellini and Bramanti, 2008). They may be labeled as gate policies, because they aim at planning and reinforcing global interface and communication functions. These functions may be embodied in tangible assets (like infrastructures for transportation and communication, institutions for international exchanges, etc.), but they crucially depend on intangible assets, such the 'culture of openness' and the sum of the relational, cognitive and reputational assets of a global nature that are available to local actors, starting with companies. The sustainability of the globalization process will depend on the balance between those assets. Gate policies may therefore be interpreted as aiming at the production, balanced accumulation and exploitation of these 'assets for internationalization'.

\section{Conclusion}

Contemporary, pragmatic industrial policies can be categorized according to a simple model (based on Schmitz, 2007) according to the way the decisions of the entrepreneurs are influenced: by being challenged or by being supported. Challenging occurs by setting targets or parameters that are consistent with the (expected) evolution of the market and the general interest. Supporting occurs by providing resources or facilitating the access to them, but also by providing conditions for the sustainability of economic change. The basic point is that only the combination of challenge and support makes up an effective industrial policy. In Figure 1 we provide a simple matrix of different policy strategies based on this idea. Where are policies located that can be suitable for market-driven companies?

In short, one may say that the low-challenge / low-support combination runs the risk to leave to the 'market' the task of finding a balanced, sustainable path of development. The risk may be too high and not acceptable.

The high-challenge/low-support combination reflects the distrust of government, but also an underestimation of the new patterns of policy making that rely on networks and governance approaches.

The high-support/low-challenge is an unrealistic approach, that clearly underestimates the increasing impossibility to constrain market-driven corporations within the horizons of closed markets.

A combination of high challenge and high support seems to be the obvious solution, with all the qualifications and specifications that have been sketched in the previous pages. One question still remain unresolved: the risk of 'policy failures', that is dramatically increased by the complexity and speed of the dynamics within the globalization process. And yet, unlike in the case of traditional industrial policies, the opportunities for collective learning made possible by the network approach should encourage more optimistic expectations. 


\section{Post-Scriptum}

The final draft of this paper had already been finished when the dramatic outbreak of the global financial crisis triggered a new wave of actions and interventions by national governments worldwide, mostly with the aim to rescue key financial actors and protect industries from the consequences of the crisis. To many this appeared as the revival of a more traditional and explicit (and less 'modest') pattern of State intervention. It is difficult to disagree with this perception. After many years in all industrial countries the role, responsibilities and powers of the State in the management of the economy was again openly discussed and acknowledged. The neo-liberal etiquette was set aside. A (hostile) commentator of the French President's proposal of a European sovereign wealth fund to buy stakes in companies with low share prices and protect them from non-European 'predators', suggested that 'the global financial crisis seems to have liberated Sarkozy to give public voice to the kind of stuff that French politicians normally save for late-night drinking sessions capitalism needs taming, the Americans are crazy, we can't have the Asians buying up our businesses, why can't the State subsidize more big industrial projects etc. etc. It's all coming out.' 1

We will need time to fully understand the meaning of these events. Nonetheless this resurgence of State interventionism should be dealt with caution. The reaction to the crisis has been slow and clumsy and governments have appeared culturally and operationally unprepared to act - that is probably one legacy of the neo-liberal age.

Moreover, their action suffered from a credibility deficit, that was only (and partially) overcome by international coordination. At the same time a consensus problem emerged. Doubts about the effectiveness and even the legitimacy of this 'New Deal' were voiced not only by the defenders of the free market ideology. Considering the immense amount of financial resources made available, numerous social and political groups challenged governments on moral and political grounds for not using these resources for other, more noble aims (such as social security, environment protection, education and research...) rather than for covering up managerial failures.

For sure, the history of industry-State relationship has not reached an end. Today, however, we should wait before guessing its new sense of direction.

Figure 1: The Matrix of Industrial Policies

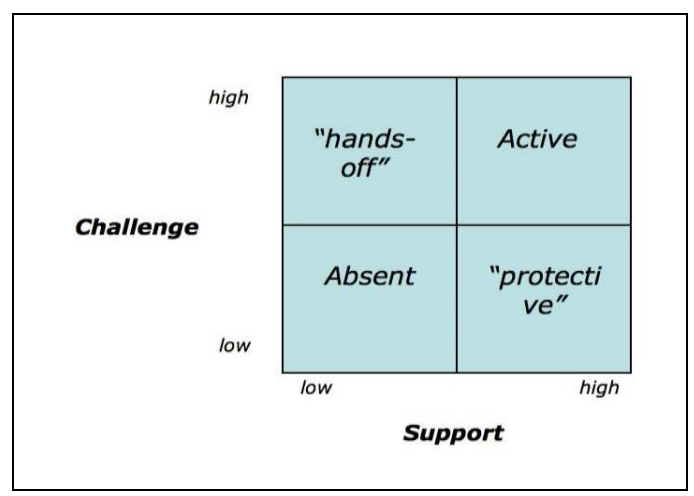




\section{Bibliography}

Atkinson M.M., Coleman W.D., Strong States and Weak States: Sectoral Policy Networks in Advanced Capitalist Economies, British Journal of Political Science, 19 January, 1989, pp. 47-67. http://dx.doi.org/10.1017/S0007123400005317

Ball G.W., Cosmocorp: The Importance of Being Stateless, The Columbia Journal of World Business, November-December, 1967, now in J.A. Frieden, D.A. Lake (eds.), International Political Economy: Perspectives on Global Power and Wealth, St. Martin's Press, New York, 1987.

Bellini N., Regional Economic Policies and the Non-Linearity of History, European Planning Studies, vol. 4, n. 1, 1996, pp. 63-73. http://dx.doi.org/10.1080/09654319608720330

Bellini N., Stato e industria nelle economie contemporanee, Donzelli, Roma, 1996.

Bellini N., The Decline of State-Owned Enterprise and the New Foundations of State-Industry Relationship, P. Toninelli (ed.), The Rise and Fall of State-Owned Enterprise in the Western World, Cambridge University Press, 2000, pp. 25-48. http://dx.doi.org/10.1017/CBO9780511896798.003

Bellini N., Business Support Policies, P. Bianchi, S. Labory (eds.), International Handbook of Industrial Policy, Edward Elgar, Cheltenham, 2006, pp. 362-379.

Bellini N., Landabaso M., Learning about Innovation in Europe's Regional Policy, R. Rutten, F. Boekema (eds.), The learning Region: Foundations, State-of-the-Art, Future, Edward Elgar Cheltenham, 2007.

Bellini N., Bramanti A., Sustainable Glocalisation: A Framework to Analyze the International Relations of Local and Regional Governments, Working paper n. 14, CERTET - Università Bocconi, 2008.

Bellini N., Bramanti A., Ongaro E. (eds), Le relazioni internazionali dei territori: economia istituzioni e società, Donzelli, Rome, 2008.

Bellini N., Loffredo A., Pasquinelli C., Managing Otherness. The Political Economy of Place Images in the Case of Tuscany, Mimeo, 2008.

Bianchi P., Labory S., From 'Old' Industrial Policy to the 'New' Industrial Development Policies, P. Bianchi, S. Labory (eds.), International Handbook of Industrial Policy, Edward Elgar, Cheltenham, 2006, pp. 3-27.

Brondoni S.M., Market-Driven Management e mercati globali, Giappichelli, Turin, 2007.

Brondoni S.M., Lambin J.J., Ouverture de 'Market-Driven Management', Symphonya. Emerging Issues in Management (symphonya.unimib.it), n. 1, 2000-2001. http://dx.doi.org/10.4468/2001.1.01ouverture

Cohen E., Theoretical Foundations of Industrial Policy, EIB Papers, vol. 11, n. 1, 2006, pp. 85-106.

Cohen E., Industrial Policies in France: The Old and the New, Journal of Industry, Competition and Trade, vol. 7, 2007, pp. 213-227. http://dx.doi.org/10.1007/s10842-007-0024-8

Cooke P., Regional Innovation Systems: Origin of the Species, International Journal of Technological Learning, innovation and Development, vol. 1, n. 3, 2008, pp. 393-409. http://dx.doi.org/10.1504/IJTLID.2008.019980

Crozier M., Etat modeste, état moderne. Strategie pour un autre changement, Fayard, Paris, 1987.

de Bruijn J.A., ten Heuvelhof E.F., Instruments for Network Management, W. Kickert, E.H. Klijn, J. Koppenjan (eds.), Managing Complex Networks. Strategies for the Public Sector, Sage, London, 1997, pp. 119-136. http://dx.doi.org/10.4135/9781446217658.n7 
Didero M., Differences in Innovation Culture Across Europe. A Discussion Paper, TRANSFORM Consortium, Bonn, 2008.

Gatti M., Cultura d'impresa, innovazione e concorrenza, S.M. Brondoni (ed.), Market-Driven Management e mercati globali, Giappichelli, Turin, 2007, pp. 131-158.

Grandinetti R., Rullani E., Impresa transnazionale ed economia globale, NIS, Rome, 1996.

Johanson J., Vahlne J., The Mechanism of Internationalisation, International Marketing Review, vol. 7, n. 1, 1990, 11-24.

Johnson C., MITI and the Japanese Miracle. The Growth of Industrial Policy, 1925-1975, Stanford University Press, Stanford, 1982.

Kickert W., Klijn E. H., Koppenjan J. (eds.), Managing Complex Networks. Strategies for the Public Sector, Sage, London, 1997. http://dx.doi.org/10.4135/9781446217658.n1

Lambin J.J., Market-Driven Management, Palgrave Macmillan, London, 2000.

Reich R.B., The Work of Nations. Preparing Ourselves for the $21^{\text {st }}$-Century Capitalism, Vintage Books, New York, 1991.

Rodrik D., Industrial Policies For The Twenty-First Century, Harvard University, John F. Kennedy School of Government, Mimeo, 2004.

Schmitz H., Reducing Complexity in the Industrial Policy Debate, Development Policy Review, vol. 25, n. 4, 2007, pp. 417-428. http://dx.doi.org/10.1111/j.1467-7679.2007.00378.x

Smith A., An Inquiry into the Nature and Causes of the Wealth of Nations, The Glasgow Edition, Oxford University Press, Oxford, 1976.

Stiglitz J.E., On the Economic Role of the State, J.E. Stiglitz (ed.), The Economic Role of the State, Basil Blackwell, Oxford, 1989.

Webster F.E., Market-Driven Management, John Wiley \& Sons, New York, 2002.

\section{Notes}

${ }^{1}$ G. Rachman on FT.com, October 22, 2008. 